\title{
Epidemiology Analysis of Poisonings with Tramadol
}

\author{
Habib Ahmadi ${ }^{1}$, Mansour Rezaie ${ }^{2}$ and Jamal Hoseini ${ }^{2 *}$
}

1 Imam Khomeini Hospital, Kermanshah University of Medical Sciences, Kermanshah, Iran

${ }^{2}$ Department of Biostatistics, Health School, Kermanshah University of Medical Sciences, Kermanshah, Iran

\begin{abstract}
It is reported that suicide was the most frequent cause of poisoning by tramadol. Seizure is a serious nervous disturbance in tramadol overdose. This study intends to characterize the poisoning with tramadol cases admitted to the Department of Emergency, Imam-Khomeini Hospital in Kermanshah, Iran. The number 1023 patients admitted from March 2008 till March 2010 were evaluated retrospectively. Information of demographic characteristics, cause of poisoning; dose of poisoning; duration of hospitalization; seizure status; co-ingestion; and mortality rate were collected from medical records of the hospital. The most poisoned subjects were bachelor $(79.8 \%)$ and 20 years old $(11.1 \%)$. Suicide $(55.1 \%)$ was the most common mode of tramadol poisoning cause. $41.8 \%$ of cases had seizure symptom and seizure incidence in male was greater than female $(P<0.001)$. correlation between dosages of used tramadol and outbreak of seizure was significant. Abuse and poisoning by tramadol led to seizure and death, and frequencies of poisoning by tramadol were among people with less than 30 years old and with the intension of suicide. The essential issue is the necessity to try to increase level of knowledge among youth regarding consumption, approaches of suicide prevention and limitation of approachability and distribution of tramadol especially in younger ages.
\end{abstract}

Keywords: Poisoning; Tramadol; Epidemiology

\section{Introduction}

Tramadol is a centrally acting analgesic used in the treatment of moderate to severe acute or chronic pain, which was first introduced in Germany in 1977. It's use has been approved in some countries since 1980 and became the most prescribed opioid worldwide [1]. In Iran, tramadol has been available since 2002 and has a widespread use [2]. Side effects of tramadol use include nausea, vomiting, drowsiness, vertigo, constipation, headache, somnolence and seizure [3]. Lethal poisonings by tramadol seems to have been increased in recent years [4-10]. Tjaderborn et al. [9] suggest that fatal intoxications with tramadol may occur unintentionally and subjects with a history of substance abuse may be at certain risks. Precaution is therefore warranted when prescribing tramadol in such patients. Shadnia et al. [10] reported tramadol overdose has been one of the most frequent causes of drug poisoning in Iran in recent years, especially in male young adults with the history of substance abuse and mental disorders, seizure and anxiety. Unconsciousness was the most common adverse CNS symptoms recorded for tramadol intoxicated subjects. Seizure is a serious nervous disturbance in tramadol overdose. In Shadnia study, majority of seizures occurred following use of high doses of tramadol. Cardiopulmonary arrest was found as the cause of death in cases who had ingested more than $5000 \mathrm{mg}$ tramadol. Death caused by tramadol generally involves multidrug poisoning [11,12]. Solarino et al. [13] reported a fatal case of multidrug poisoning by tramadol and nicotine and determined the cause of death to be cardiorespiratory failure induced by the additive effects of tramadol and nicotine shortly after consumption.

The cause of poisoning with tramadol can be intentional (suicide or homicide) or unintentional. Clarot et al. [8] reported that most of the patients attempted suicide by tramadol. Shadnia et al. [10] reported suicide was the most common mode of poisoning by tramadol.

Therefore, the knowledge of the model of poisoning with tramadol in a particular region would help in early diagnosis and management of poisoning, which in turn should result in the reduction of morbidity and mortality. The present study was undertaken to provide such information during two years. However, no study of poisonings with tramadol involving two years and over 1000 cases has been published so far.

Based on this, we decided to investigate an epidemiologic study of tramadol intoxications by using data of emergency department in Imam-Khomeini Hospital of Kermanshah in Iran. Imam-Khomeini Hospital is a reference Hospital of poisoning in Kermanshah that provides services to a wide variety of people of Kermanshah with a population of about 2000000 and people from neighbor provinces.

\section{Materials and Methods}

\section{Subjects and Data collection}

The subjects were selected from all of the poisonings with tramadol admitted to Department of Emergency, Imam-Khomeini Hospital, from March 2008 to March 2010. Data were collected from the medical records of patients that were completed by hospital MD and interns. The information obtained from conscious patients or their relatives was the basis of diagnosis of intoxication with tramadol or co-ingested compounds.

\section{Variables}

The variables of study: Demographic information including gender, age, and marital status, cause of poisoning, dose of poisoning, duration of hospitalization, seizure status, co-ingestion and mortality were recorded.

*Corresponding author: Jamal Hoseini, Department of Biostatistics, Health School, Kermanshah University of Medical Sciences, Kermanshah, Iran, Tel: +98 831 8262052; Fax: +98 831 8264447; E-mail: jhoseini2003@yahoo.com

Received August 23, 2011; Accepted April 19, 2012; Published April 21, 2012

Citation: Ahmadi H, Rezaie M, Hoseini J (2012) Epidemiology Analysis of Poisonings with Tramadol. J Forensic Res 3:151. doi:10.4172/2157-7145.1000151

Copyright: ( 2012 Ahmadi $\mathrm{H}$, et al. This is an open-access article distributed under the terms of the Creative Commons Attribution License, which permits unrestricted use, distribution, and reproduction in any medium, provided the original author and source are credited. 
Citation: Ahmadi H, Rezaie M, Hoseini J (2012) Epidemiology Analysis of Poisonings with Tramadol. J Forensic Res 3:151. doi:10.4172/21577145.1000151

Page 2 of 4

\section{Statistical analysis}

Statistical analyses were conducted using SPSS for Windows Version 18.0 pocket program. Mean, median, Standard Deviation (SD) and upper $90^{\text {th }}, 95^{\text {th }}$ and $97.5^{\text {th }}$ percentiles were used as descriptive statistics. After the evaluation of our data, the results showed a normal distribution and therefore we used nonparametric approach and chisquare test. A probability level of $\mathrm{p}<0.05$ was considered significant.

\section{Results}

\section{Age, Gender and Marital}

A number of 883169 cases with poisoning referred to the emergency department of Imam-Khomeini Hospital during the period of 2 years (from March 2009 till March 2010). 1023 patients with tramadol poisoning were identified as $803(78.5 \%)$ males and $220(21.5 \%)$ females, which constitutes ratio of 3.6. Figure 1 shows the distribution of patients in terms of age. The median age at presentation was 21 years, mean 22.7 years. Children under 15 years of age represented the $2.2 \%$ $(\mathrm{n}=12)$ of patients whereas adults between 16 and 35 years were the 93.3\% $(\mathrm{n}=955)$.

From 1023 patients of tramadol poisoning, 79.8\% weren't married and $20.2 \%$ were married. Difference between mean of age of bachelor $(21.63 \pm 5.38)$ and married cases $(27.13 \pm 8.34)$ is significant $(\mathrm{P}<0.05)$. In men, $84.9 \%(\mathrm{n}=675)$ weren't married and $15.1 \%(\mathrm{n}=120)$ were married. Also, in women, $61.2 \%(\mathrm{n}=134)$ weren't married and $38.8 \%(\mathrm{n}=85)$ were married.

\section{Dosage, Cause and Seizure}

Most common mode of used dosage was less than $1000 \mathrm{mg}$ (42.1\%). Table 1 shows the distribution of dosage of tramadol. Chi-square of tests showed association between dosage of tramadol and gender is significant $(\mathrm{P}<0.05)$.

The most frequent cause of poisoning by tramadol was suicide (55.1\%). of course, for women the most cause was drug use (38.8\%). Chi-square of tests showed association between cause of poisoning by tramadol and gender is significant $(\mathrm{P}<0.05)$, and association between cause of poisoning by tramadol and age is significant $(\mathrm{P}<0.05)$. Association between cause of poisoning by tramadol and marital status is significant $(\mathrm{P}<0.05) .74 .7 \%$ of cases $(\mathrm{n}=413)$ of poisoning by tramadol was suicide, whose gender was male. $92.7 \%$ of cases $(n=507)$ of poisoning by tramadol was suicide, whose age range was lower than

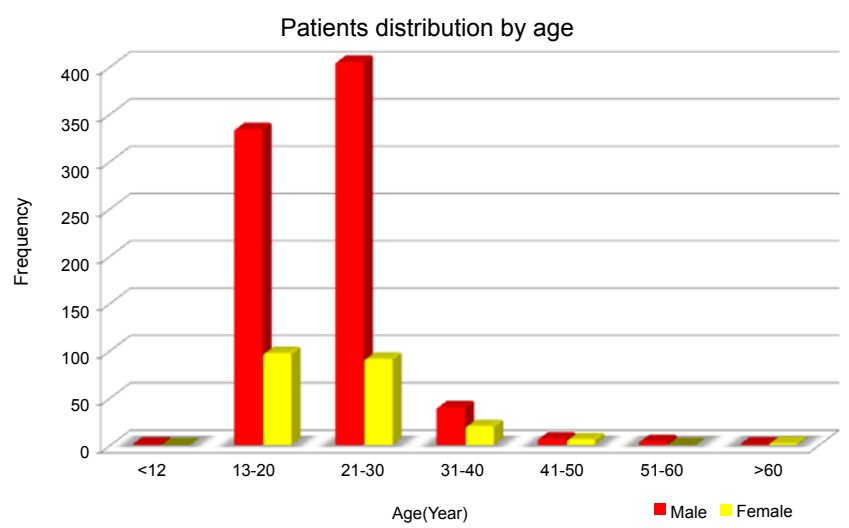

Figure 1: Patients distibution by age. The commonest age group involved in poisoning by tramadol was between 21 and 30 years.

\begin{tabular}{|c|c|c|c|c|c|c|}
\hline \multirow{2}{*}{ Dosage of Tramadol } & \multicolumn{2}{|c|}{ women } & \multicolumn{2}{c|}{ men } & \multicolumn{2}{c|}{ Total } \\
\cline { 2 - 7 } & Count & $\%$ & Count & $\%$ & Count & $\%$ \\
\hline Less of 1000 & 88 & 40 & 342 & 42.6 & 430 & 42 \\
\hline $1000-2000$ & 49 & 22.3 & 134 & 16.7 & 183 & 17.9 \\
\hline $2000-3000$ & 33 & 15 & 101 & 12.6 & 134 & 13.1 \\
\hline $3000-4000$ & 8 & 3.6 & 59 & 7.4 & 67 & 6.6 \\
\hline $4000-5000$ & 5 & 2.3 & 35 & 4.3 & 40 & 3.9 \\
\hline More & 6 & 2.7 & 37 & 4.6 & 43 & 4.2 \\
\hline Missing* & 31 & 14.1 & 95 & 11.8 & 126 & 12.3 \\
\hline Total & 220 & 100 & 803 & 100 & 1023 & 100 \\
\hline
\end{tabular}

* Dosage of tramadol for 126 of cases not reported.

Table 1: Distribution of poisoning cases according to dosage of tramadol.

30 year. $80.4 \%$ of cases $(n=444)$ of poisoning by tramadol was suicide whose marital status was bachelor.

$41.8 \%$ of cases $(n=428)$ have symptoms of seizure and other cases haven't symptoms of seizure. Chi-square of tests showed association between outbreak of seizure and gender is significant $(\mathrm{P}<0.05)$, and association between outbreak of seizure and age is significant $(\mathrm{P}<0.05)$. $87.6 \%$ of cases $(n=375)$ that have symptoms of seizure, their genders was men, also $94 \%$ of cases $(n=392)$ that have symptoms of seizure, their age ranges was lower than 30 year.

Figure 2 shows the distribution of Frequency of dosage of tramadol by outbreak of seizure. Chi-square of tests showed association between outbreak of seizure and dosage of tramadol is significant $(\mathrm{P}<0.05)$, and association between outbreak of seizure and cause of poisoning by tramadol is significant $(\mathrm{P}<0.05)$, also association between dosage of tramadol and cause of poisoning by tramadol is significant $(\mathrm{P}<0.05)$. $60 \%$ cases of poisoning were unintentional and symptoms of seizure were observed. Also, $65 \%$ cases of poisoning were abuse and symptoms of seizure were observed.

\section{Duration of hospitalization, History of tramadol addiction, co-ingested drug with tramadol}

Duration of hospitalization for $94.2 \%$ of cases $(n=693)$ were shorter than 48 hours. Chi-square of test showed association between duration of hospitalization and dosage of tramadol is significant $(\mathrm{P}<0.05)$. History of tramadol addiction were reported in the $29.6 \%$ $(n=303)$ of cases; overall, $88.4 \%$ was seen in males. The history of tramadol addiction was reported for $85.8 \%$ of cases $(n=260)$, whose were poisoned by tramadol addict. $21.6 \%$ of cases $(n=221)$ co-ingested drug with tramadol, which benzodiazepines (46.1\%) were the most common. Chi-square of test showed association between outbreak of seizure and co-ingested drug with tramadol is significant $(\mathrm{P}<0.05)$, $49 \%$ cases that ingested drug with tramadol were not reported and symptoms of seizure were observed. Also, $44.2 \%$ cases that ingested benzodiazepine with tramadol, consumed less than $1000 \mathrm{mg}$ dosage of tramadol.

\section{Mortality}

Results indicated that $10(10 \%)$ of the admitted cases died. Table 2 shows the characteristics of dead cases. $90 \%$ of dead cases were males. The mean age was 30 years. The most common cause of death was suicide (60\%). In $70 \%$ of cases symptoms of seizure were seen.

\section{Discussion}

In this study 1023 tramadol intoxications were identified during the 2-year study period. As far as age and gender distributions, are concerned tramadol intoxications affect mainly young men with the 


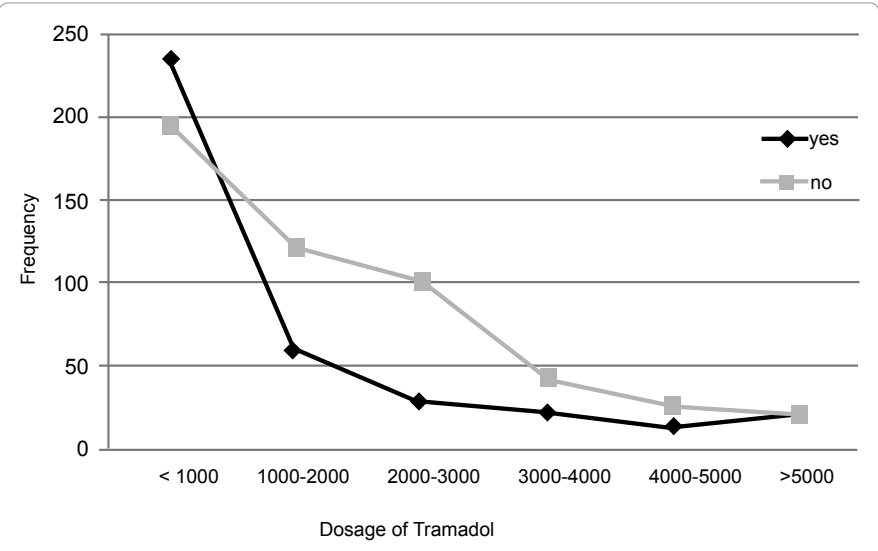

Figure 2: Frequency of dosage of tramadol by outbreak of seizure.

\begin{tabular}{|c|c|c|c|c|c|c|c|}
\hline Case & Age(Year) & Gender & Marital & Cause & Seizure & Dosage & $\begin{array}{c}\text { Drug with } \\
\text { tramadol }\end{array}$ \\
\hline 1 & 28.00 & Male & Bachelor & Suicide & No & 1000 & Other $^{+}$ \\
\hline 2 & 25.00 & Male & Bachelor & Addict & Yes & $\begin{array}{c}1000- \\
2000\end{array}$ & No \\
\hline 3 & 22.00 & Male & Bachelor & Suicide & Yes & 1000 & Other \\
\hline 4 & 41.00 & Male & Marital & Suicide & No & Missing & No \\
\hline 5 & 68.00 & Male & Marital & Addict & Yes & 1000 & Other \\
\hline 6 & 22.00 & Male & Bachelor & Addict & Yes & $\begin{array}{c}2000- \\
3000\end{array}$ & Other \\
\hline 7 & 30.00 & Male & Bachelor & Suicide & Yes & Missing & No \\
\hline 8 & 24.00 & Female & Marital & Missing & Yes & $\begin{array}{c}1000- \\
2000\end{array}$ & BZD \\
\hline 9 & 24.00 & Male & Bachelor & Suicide & Yes & $\begin{array}{c}1000- \\
2000\end{array}$ & No \\
\hline 10 & 16.00 & Male & Bachelor & Suicide & No & $\begin{array}{c}2000- \\
3000\end{array}$ & No \\
\hline
\end{tabular}

*Benzodiazepine

+ Codeine, morphine and other drugs.

+ not reported.

Table 2: Characteristics of dead cases.

most represented age gender range 16 to 35 years. The number of victims is almost threefold as high as women in the same age bracket, as reported in similar studies $[3,8,10]$. Bachelor cases get involved in tramadol intoxications more frequently and seriously than married cases. The reason is most likely to be found in the onus for family and it is in accordance with other study [10]. The results show that suicide was the most cause of intoxication, which doesn't match reports from France, USA and Iran $[3,8,10]$. The present study indicated that most of suicide attempts occur in the age group of 12-30 years and in bachelors, which seems to be in relation with youth characteristics. This is comparable with the general pattern of acute human poisonings in Tehran-Iran during 1 year [14]. Most of the patients use the dosage of less than $1000 \mathrm{mg}$. This finding is in agreement with Shadnia study in 2008 [10]. The reason could be related to inexperience of cases in consuming of tramadol. As shown in Figure 2, dosage of tramadol affect on outbreak of seizure. The reason could be related to increasing of chance that outbreak of seizure in inexperienced cases with low dosage. In the present study, above of $50 \%$ of the cases that cause of poisoning were unintentional or abuse, seizure happen for them. Our report of duration of hospitalization is higher than previous reports $[3,10,15]$. Of course, in this study, dosage of tramadol affect on duration of hospitalization for patients. In the present study, history of tramadol addiction observed. Therefore, most history of tramadol addiction occurs in the addict cases. Indeed, virtually all reported tramadol poisonings have been reported in conjunction with the detection of other drugs. For example, benzodiazepines were co-ingested with tramadol, as reported in similar studies [5,8,10-11,16-19]. In this study, benzodiazepine was co-ingested with tramadol in most of cases and can increase the risk of intoxication, especially in the presence of low doses of tramadol. This is similar to other reports [3,10-11]. Fatal reports after tramadol poisoning and overdose have been seldomly reported. The mortality of acute poisoning depends on a number of factors such as nature of poison, dose consumed, level of available medical facilities and the time interval between intake of poison and arrival at hospital [5-15]. Finally, mortality rate of tramadol poisoning was $0.97 \%$. Comparing the present result with previous study, a decrease in the mortality rate of tramadol poisoning is confirmed $[6,10,20]$. In conclusion, Abuse and poisoning by tramadol lead to seizure and death and the high rate of tramadol poisonings was in young men. Tramadol poisonings had higher mortality and morbidity rates in men than in women. Suicide was the major cause of poisoning by tramadol. Seizure was noted mainly in young men. Building poisoning centers, those actually are inadequate in the country. The essential issue is the necessity to try to increase level of knowledge among youth regarding consumption, approaches of suicide prevention and limitation of approachability and distribution of tramadol especially in younger ages.

\section{References}

1. Shipton EA (2000) Tramadol-present and future. Anaesth Intensive Care 28: 363-374.

2. Gholami K, Shalviri G, Zarbakhsh A, Daryabari N, Yousefian S (2007) New guideline for tramadol usage following adverse drug reactions reported to the Iranian pharmacovigilance center. Pharmacoepidemiol Drug Saf 16: 229-237.

3. Marquardt KA, Alsop JA, Alberton TE (2005) Tramadol exposures reported to statewide poison control system. Ann. Pharmacother 39: 1039-1044.

4. Klotz F, Petersson A, Isacson D (2007) Violent crime and substance abuse: a medico-legal comparison between deceased users of anabolic androgenic steroids and abusers of illicit drugs. Forensic Sci Int 173: 57-63.

5. De Decker K, Cordonnier J, Jacobs W, Coucke V, Schepens P, et al. (2008) Fatal intoxication due to tramadol alone case report and review of the literature. Forensic Sci Int 175: 79-82.

6. Musshoff F, Madea B (2001) Fatality due to ingestion of tramadol alone Forensic Sci. Int. 116: 197-199.

7. Jonsson AK, Holmgren P, Druid H, Ahlner J. (2007) Cause of death and drug use pattern in deceased drug addicts in Sweden, 2002-2003. Forensic Sci. Int 169: 101-107

8. Clarot F, Goulle JP, Vaz E, Proust B (2003) Fatal overdoses of tramadol: is benzodiazepine a risk factor of lethality. Forensic Sci Int 134: 57-61.

9. Tjäderborn $M$, Jönsson AK, Hägg $S$, Ahlner J (2007) Fatal unintentiona intoxications with tramadol during 1995-2005, Forensic Sci Int 173: 107-111.

10. Shadnia S, Soltaninejad K, Heydari K, Sasanian G, Abdollahi M (2008) Tramadol intoxication: a review of 114 cases. Hum Exp Toxicol 27: 201-205.

11. Michaud K, Augsburger M, Romain N, Giroud C, Mangin P (1999) Fatal overdose of tramadol and alprazolam, Forensic Sci. Int 1999;105: 185-189.

12. Clarkson JE, Lacy JM, Fligner CL, Thiersch N, Howard J, et al. (2004) Tramadol (UltramR) concentrations in death investigation and impaired driving cases and their significance, J Forensic Sci 49: 1101-1105.

13. Solarino B, Riesselmann B, Buschmann CT, Tsokos M (2010) Multidrug poisoning involving nicotine and tramadol. Forensic Sci Int 194: e17-e19.

14. Shadnia S, Esmaily $H$, Sasanian G, Pajoumand A, Hassanian-Moghaddam $\mathrm{H}$, et al. (2007) Pattern of acute poisoning in Tehran-Iran in 2003. Hum Exp Toxicol 26: 753-756.

15. Spiller HA, Gorman SE, Villalobos D, Benson BE, Ruskosky DR, et al. (1997) 
Citation: Ahmadi H, Rezaie M, Hoseini J (2012) Epidemiology Analysis of Poisonings with Tramadol. J Forensic Res 3:151. doi:10.4172/21577145.1000151

Page 4 of 4

Prospective multicenter evaluation of Tramadol exposure. J Toxicol Clin Toxicol 35: 361-364.

16. Ripple MG, Pestaner JP, Levine BS, Smialek JE (2000) Lethal combination of tramadol and multiple drugs affecting serotonin. Am J Forensic Med Pathol 21: $370-374$

17. Goeringer KE, Logan BK, Christian GD (1997) Identification of tramadol and its metabolites in blood from drug-related deaths and drug-impaired drivers. $J$ Anal Toxicol 21: 529-537.
18. Bynum ND, Poklis JL, Gaffney-Kraft M, Garside D, Ropero-Miller JD (2005) Postmortem distribution of tramadol, amitriptyline, and their metabolites in a suicidal overdose. J Anal Toxicol 29: 401-406.

19. Levine B, Ramcharitar V, Smialek JE (1997) Tramadol distribution in four postmortem cases. Forensic Sci Int 86: 43-48.

20. Daubin C, Quentin C, Goullé JP, Guillotin D, Lehoux P, et al. (2007) Refractory shock and asystole related to Tramadol overdose. Clin Toxicol (Phila) 45 961-964. 